\title{
The Positive Effect of Contradictory Information: The Effect of Verbal/ Nonverbal Discrepancy on Brand Attitudes in the Short Term and the Long Term
}

\author{
Michal Shapira*, Moty Amar and Tsfira Grebelsky-Lichtman
}

Department of Business Administration, Ono Academic College and Department of Communication, The Hebrew University of Jerusalem, Israel

\begin{abstract}
While the field of verbal/nonverbal discrepancy has gained increasing interest in recent years, research in this area related to the effect of discrepant communication on brand attitudes received considerably less attention. This research uncovers a counterintuitive positive persuasive effect of contradictory information, showing that specifiable conditions will be more favorably disposed to a brand attitude when verbal/nonverbal discrepancy is expressed than an otherwise particular type of verbal/nonverbal congruency. This effect was revealed using an experimental design, and was explored both in the short term and in the long term. Participants were exposed to a persuasive message regarding a new brand product and were randomly assigned to four conditions: positive congruency $(\mathrm{V}+\mathrm{N}+)$, negative congruency ( $\mathrm{V}-\mathrm{N}-)$, leakage discrepancy $(\mathrm{V}+\mathrm{N}-)$, and adaptive discrepancy $(\mathrm{V}-\mathrm{N}+)$. The novel findings indicated that adaptive discrepancy $(\mathrm{V}-\mathrm{N}+)$, had the highest persuasive effect on brand attitudes in the long run. However, leakage discrepancy $(\mathrm{V}+\mathrm{N}-)$, had a negative effect on brand attitudes, particularly in the long run, eliminating the sleeper effect. The present research expands the multimodal communication approach by presenting an analytical and theoretical framework that delineates the complex persuasive effects of verbal/nonverbal interrelations. Finally, the research develops reliance theory and developmental interactionist theory, regarding nonverbal primacy in persuasion.
\end{abstract}

Keywords: Nonverbal communication; Verbal communication; Discrepancy; Multimodal communication; Sleeper effect; Nonverbal primacy

\section{Introduction}

What effect emerges when confronting a persuasion message that contains a verbal versus nonverbal discrepancy on brand attitude? This theoretical and practical question is approached from a multimodal communication perspective that focuses on the interaction of verbal and nonverbal patterns on brand attitude. This research contributes by presenting an analytical and theoretical framework that conceptualizes the interaction between verbal and nonverbal modalities and shows the positive effect of particular patterns of verbal and nonverbal discrepancy on brand attitude. The current research explains the influence of various patterns of verbal and nonverbal discrepancy/ congruency and delineates the multimodal communication effect on brand attitudes in both the short term and the long term. Finally, this research presents a complex theoretical account that bridges the effect of discrepant information and the sleeper effect on brand attitude and contributes to reliance theory of verbal versus nonverbal primacy.

\section{Multimodal communication approach}

The theoretical framework of this study draws on a multimodal communication approach that emphasizes the importance of examining the mutual relations between verbal and nonverbal modes of communication [1]. Verbal and nonverbal communications are present in face-to-face interactions in a way that constitutes an integrative event. Addressees receive verbal message accompanied by nonverbal messages, and the way in which the overall message is perceived is determined by the relationship between the two modes [2].

Recently, research into the relationship between verbal and nonverbal communication has advanced as new and more complex approaches have been introduced [3]. A current trend is to carry out integrative research that recognizes the need to assess the interconnections of verbal and nonverbal communication [4]. This examination explains the ways in which vocal and visible behaviors are associated with one another, and explores the interrelationships between different modalities of communication [5]. The present research argues that a combined examination of verbal and nonverbal communication and the relationship between them can provide new insights into the study of persuasion and brand attitudes.

The relationship between verbal and nonverbal modes of communication is conceptualized based on the distinction between two types of links: congruency and discrepancy [6]. The link of congruency is when there is a relationship of identity or similarity between the messages: the overall message is coherent, and the verbal and nonverbal messages are mutually enhancing. Congruent communication is associated with certainty, an unequivocal message [7]. A theoretical perspective in game theory has suggested that communication patterns characterized by "sending accuracy" that are, the exactness with which an individual communicates messages is associated with congruence behavior [8]. Congruency presents a message that is certain, consistent, and clear. Consequently, it is associated with credibility and trust and is considered an effective pattern of communication, which may create an optimal condition for persuasion and achieving agreement [9].

The link of discrepancy exists when there is a contradiction or

*Corresponding author: Michal Shapira, Senior Lecturer, Department of Business Administration, Ono Academic College, Ono Academic College Business Administration, 104 Zahal St., Kiryat Ono 55000 Israel, Tel: 972-544990444; E-mail: mshapira@ono.ac.il

Received August 16, 2017; Accepted August 30, 2017; Published Septembe 07, 2017

Citation: Shapira M, Amar M, Grebelsky-Lichtman T (2017) The Positive Effect of Contradictory Information: The Effect of Verbal/Nonverbal Discrepancy on Brand Attitudes in the Short Term and the Long Term. J Account Mark 6: 253. doi: 10.4172/2168-9601.1000253

Copyright: $\odot 2017$ Shapira M, et al. This is an open-access article distributed under the terms of the Creative Commons Attribution License, which permits unrestricted use, distribution, and reproduction in any medium, provided the original author and source are credited. 
Citation: Shapira M, Amar M, Grebelsky-Lichtman T (2017) The Positive Effect of Contradictory Information: The Effect of Verbal/Nonverbal Discrepancy on Brand Attitudes in the Short Term and the Long Term. J Account Mark 6: 253. doi: 10.4172/2168-9601.1000253

incongruence between verbal and nonverbal messages [10]. This type of communication occurs when there is inconsistency and mismatch between the communication modes [11]. Recent studies have indicated that discrepant communication is frequently expressed in interpersonal interactions [3]. In some interactions, discrepant communication is minor and hardly expressed, but there are interactions in which most of the messages represent verbal and nonverbal discrepancy [12]. According to discrepancy arousal theory, discrepant communication has a negative influence on mutually expressive behavior [13]. Moreover, discrepancy affects perceptions negatively, especially those of reliability and trust, attitudes, cooperation, and behavioral trends [6].

The present research conceptualizes diverse congruent and discrepant communication patterns along two axes: verbal/nonverbal communication modes and positive/negative message. As can be seen in Figure 1, the combination of these two axes produces four comprehensive types of congruence and discrepant communication. This research expands the existing theoretical framework by delineating the effect of various verbal and nonverbal interrelations on brand attitudes. The presented framework illuminates a new set of research questions regarding the effect of verbal/nonverbal discrepancy/ congruency on brand attitudes:

RQ1: What happens to an attitude toward a brand when exposing to discrepant communication patterns that contain a verbal and nonverbal mismatch?

RQ2: What happens to an attitude toward a brand when exposing to congruent communication patterns in which there is consistency between the two communication modes?

The proffered framework of verbal/nonverbal interactions delineates a variety of relationships between verbal and nonverbal communication modes and accounts for their effect on persuasion, in terms of effective versus inhibitory communication patterns. As illustrated in Figure 1, congruent and discrepant patterns are divided into effective categories and inhibitory categories, each of which contains both congruent and discrepant communication patterns. The effective categories include positive congruency (an expression of both verbal and nonverbal positive messages) and adaptive discrepancy (an expression of negative verbal message and positive nonverbal message). Positive congruency presents a message that is certain, consistent, and clear. Consequently, it is associated with credibility and trust and considered an effective pattern of communication [9]. Positive congruency increases cooperation, promotes listening, and enhances the relationships between the partners to the interaction [14]. Thus, positive congruency creates an optimal condition for persuasion and achieving agreement.

Adaptive discrepancy, which contains a negative verbal message accompanied with a positive nonverbal message, is also defined as an effective pattern. In this pattern, the adaptive meaning is explained by the fact that the negative verbal communication is received in a context of positive nonverbal content, and is therefore perceived as specific, less threatening, and impersonal. Positive nonverbal expression conveys a message of security and calmness that puts some distance from the negative verbal message, while the person expressing the message radiates an impression of being strong and supportive [15]. This pattern mitigates the negative verbal message and helps establish a credible image of self-confidence, ease, and control. This type of discrepancy enhances cooperation [16] and expresses a pattern in which the gap between the channels and the verbal negative information may have positive value for communication and persuasion.

The inhibitory categories include negative congruency (an expression of both verbal and nonverbal negative messages) and leakage discrepancy (an expression of positive verbal message and negative nonverbal message); (Figure 1).

Negative congruency involves verbal and nonverbal negative messages. Even though this pattern of communication is congruent, it can be scathing and hurtful in terms of the ways in which the message and the sender are perceived [17]. In regard to negative congruency, although persuasion theories argue that negative information may be more persuasive than positive information [18], recent studies have suggested that an overly negative message can arouse dislike and undermine the credibility of the sender and of the message [19-21]

Leakage discrepancy is characterized by positive verbal communication and negative nonverbal communication [10]. Leakage is inversely proportional to potential control, such that more controlled communication modes are less leaky [6]. Communication modes with

Positive

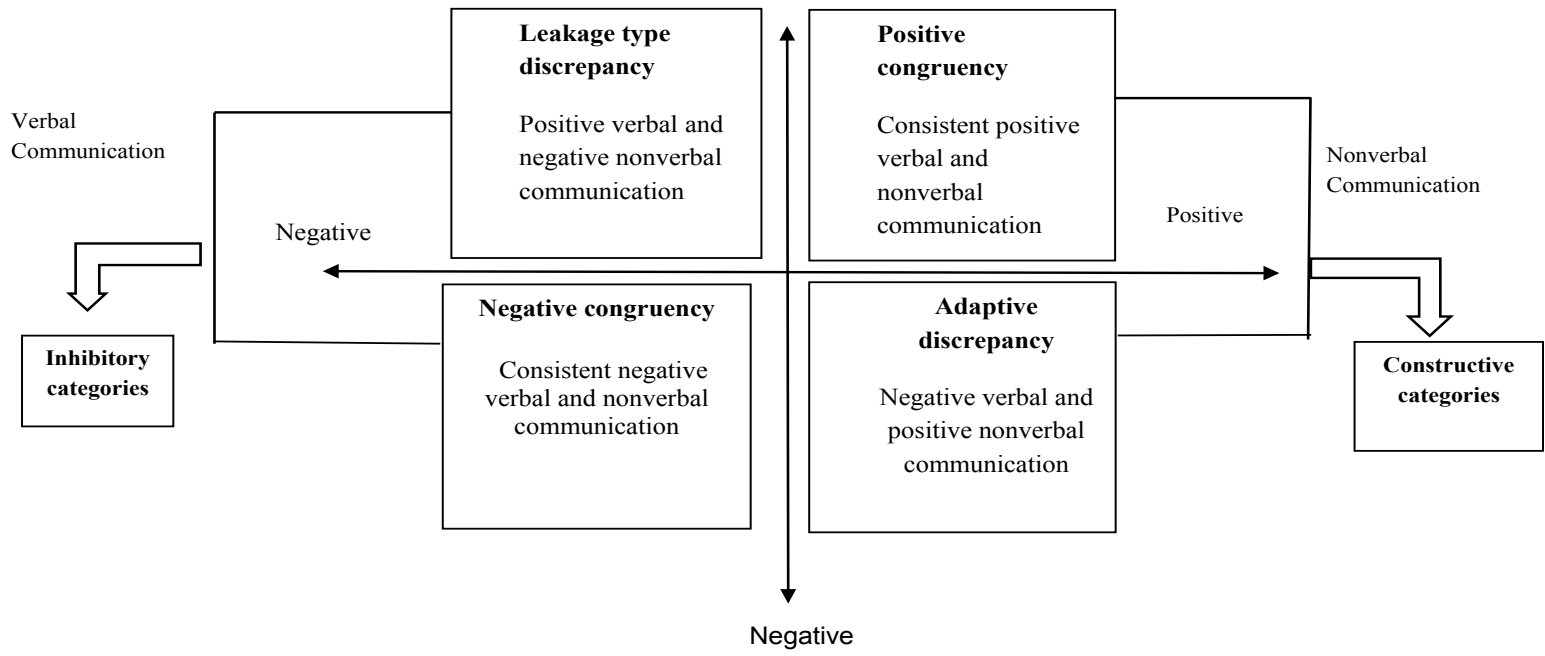

Figure 1: Multimodal constructive and inhibitory communication patterns. 
less control involve a higher probability that concealed information will be revealed involuntarily [22]. Thus, the nonverbal communication mode, which tends to be less controlled, will be the "leakier" mode of communication [23].

Leakage discrepancy constitutes a central theme in the literature that addresses interactions involving deception or even lies [24,25]. People who lie tend to choose their words very carefully, but their real emotions "leak" out nonverbally, primarily through their tone of voice and body language [26]. This is the basis for lie detectors that check physiological reactions [6]. Research into leakage discrepancy has suggested that these discrepant messages can have inhibitive emotional and social implications and has viewed them as a source of misunderstanding and communicative "short circuits" that interrupt the flow of the interaction [12].

Following impression management theory, leakage discrepancy affects the credibility of the addressor [25]. Based on extensive research on the role of source credibility as a major context factor in persuasion and its role as a manipulation of discounting cues in the literature, leakage discrepancy, in which the negative information is attributed to highly credible source (the nonverbal mode of communication), will have a negative effect on persuasion.

The presented framework demonstrates that not all congruency is effective for persuasion and that not all discrepancy is inhibitive (Figure 1). This framework makes it possible to formulate a set of hypotheses regarding the effect of verbal and nonverbal relationships on brand attitude, which identify patterns that should be beneficial or detrimental for persuasion. Thus, we formulated the following hypotheses:

H1a: Participants exposed to positive congruency $(\mathrm{V}+\mathrm{N}+)$ will show more positive product attitudes than participants exposed to leakage discrepancy $(\mathrm{V}+\mathrm{N}-)$, in which the nonverbal message composed a negative information.

H1b: Participants exposed to negative congruency (V-N-) will show less positive product attitudes than participants exposed to adaptive discrepancy $(\mathrm{V}-\mathrm{N}+)$, in which the verbal message contained a negative information.

\section{The long-term effect of verbal/nonverbal interactions on brand attitude: Bridging the multimodal communication approach and the sleeper effect}

The aim of this research is to expand the existing literature of multimodal communication by analyzing the long-term effect of verbal/ nonverbal discrepancy/congruency on brand attitude. This research contributes by bridging multimodal communication approach and sleeper effect, which illuminates the following novel research questions:

RQ3: What happens to an attitude toward a brand when exposing to a congruent message that contains consistent information in both communication modes over time?

RQ4: What happens to an attitude toward a brand when exposing to a discrepant message that contains negative information (a discounting cue) in one communication mode over time?

The sleeper effect is conceptualized as a phenomenon in which people receive a communication message that contains a discounting cue, and the effect of the discounting cue dissipates over time and the negative impact decreases $[27,28]$. That is, the discounting cue has a stronger effect immediately after the exposure than after the elapse of time [29]. Over time, the message and the discounting cue become dissociated and the impact of message-related knowledge increases (after initially having been suppressed). This, in turn, facilitates attitude change [30] and results in a delayed increase in the impact of the message over time. In other words, the delayed impact of a message is more effective than the initial reaction [31]. The sleeper effect is counterintuitive because the impact of a persuasive communication is generally greater when one measures the effect closer in time to presentation rather than after the elapse of time after reception [27].

The sleeper effect has attracted significant scientific attention $[27,28]$. Various explanations have been offered for the process that underlies the sleeper effect. Hovland et al. [32] initially explained the effect in terms of the forgetting hypothesis, which assumes that the effect occurs as a result of faster forgetting of the discounting cue. This explanation was subsequently developed by Hovland and Weiss [33] into the dissociation hypothesis, which claims that the message and source are remembered over time, but are dissociated. Therefore, joint recall of the two items of information fails at delayed measurement when the persuasive influence of the message is no longer suppressed by the discounting source. Miller and Campbell [34] based their explanation on primacy-recency analysis, which assumes that information presented last is more accessible (recency effect), while information presented first is processed more intensively and therefore more endurable (primacy effect). Hannah and Sternthal [35] developed the availability valence hypothesis, which suggests that attitude change is due to the valence and availability of relevant associations. At the outset, unfavorable source characteristics suppress associations with favorable message content because the source is more available. At the time of delayed measurement, message associations become more available due to primacy. The differential decay interpretation explains the Sleeper effect as the joint result of the impact of two items of information decaying at a different pace. At immediate measurement, the more recent information (that is, the source) is predominant; the message is processed more intensively due to its primacy, and its impact decays at a slower rate. When bridging the multimodal communication approach and the sleeper effect, the following hypotheses are advanced:

H2a: Participants exposed to persuasive message of constructive patterns (positive congruency condition and adaptive discrepancy condition) will show a decline in positive product attitudes over time.

H2b: Participants exposed to persuasive messages of inhibitory patterns (negative congruency condition and leakage discrepancy condition) will demonstrate an increase in product attitudes over time.

\section{The effect of verbal versus nonverbal primacy on brand attitude}

The present research contributes to the reliance theory of verbal versus nonverbal primacy. The concept of primacy refers to the state of being dominant, more important, or contributing more [2]. When discrepancy exists, an intriguing question is raised, which question lies at the heart of this research:

RQ5: Which channel (verbal or nonverbal) contributes more to persuasion and brand attitudes?

The theoretical foundations for verbal versus nonverbal primacy are conceptualized in reliance theories and channel-summation research, which determine which types of cues (verbal or nonverbal) are more influential in the perceptions of participants exposed to discrepant communication. The current research expands reliance theories by presenting a novel framework for analyzing verbal versus nonverbal 
Citation: Shapira M, Amar M, Grebelsky-Lichtman T (2017) The Positive Effect of Contradictory Information: The Effect of Verbal/Nonverbal Discrepancy on Brand Attitudes in the Short Term and the Long Term. J Account Mark 6: 253. doi: 10.4172/2168-9601.1000253

Page 4 of 10

primacy. The proposed framework uniquely explores the effect of various discrepant patterns of verbal versus nonverbal message. This analysis contributes to comprehensive accounts of the effect of diverse patterns of discrepant communication.

The present research analyzed various discrepant patterns: when the discounting cue is expressed in verbal communication (adaptive discrepancy), or in nonverbal communication (leakage discrepancy). This research investigates the effect of discounting information (that is, information designed to undermine the original persuasive message) expressed by different communication modes on persuasion in the short term and the long term, as defined by the brand attitudes toward the original message.

Regarding the long-term effect, according to the sleeper effect, recipients of a persuasive message with a discounting cue are expected to express less-positive attitudes towards the brand than recipients who have not been exposed to a discounting cue. In measures of delayed attitudes, however, the discounting cue recipients are expected to show a more positive attitude, while participants exposed to the positive congruent message (whose members were exposed to the persuasive message without receiving a discounting cue) are expected to show a decline in positive attitudes toward the brand over time.

The comparative analysis of a discounting cue in different modes of communication develops the central question of verbal versus nonverbal primacy in persuasion and delineates various effects of discrepant communication for the short and the long term on brand attitude.

\section{Method}

\section{Participants}

The immediate effect of multimodal communication (first measurement): Four hundred twenty-four undergraduates participated in the first measurement of the experiment. The participants were randomly assigned to each of the four groups of conditions. Participants' mean age was 31.4, ranging from age 24 to 46; $\mathrm{SD}=6.7$. A total of 218 participants were male (51.4\%) and 206 participants were female (48.6\%). Participants' marital status was: married (45.8\%), single (47.6\%), and divorced (6.6\%).

The long-term effect of multimodal communication (second measurement): Although four hundred twenty-four participants took part in the immediate measurement prior to this second measurement, 404 completed the questionnaire at the second measurement, with a delay of two weeks. The mean age of these participants was 30.6, ranging from age 24 to $46 ; 198$ participants were male (49\%) and 206 participants were female $(51 \%)$. Participants' marital status was: married (41.6\%), single (52.6\%), and divorced (5.8\%).

\section{Design}

Participants were exposed to information, screened on video, regarding a new brand product and were randomly assigned to one of the following four conditions:

1. Positive congruency condition: Participants in this group were exposed to positive congruent persuasive message and were not exposed to a discounting cue. In this condition both verbal and nonverbal messages were positive.

2. Leakage discrepancy condition: Nonverbal discounting cue condition. Participants in this group were exposed to a leakage discrepancy pattern with a discounting cue (the nonverbal cues were negative while the accompanied verbal messages were positive).

3. Negative congruency condition: Participants in this group were exposed to a negative congruency message. In this condition, both verbal and nonverbal messages were negative.

4. Adaptive discrepancy condition: Verbal discounting cue condition. Participants in this group were exposed to adaptive discrepancy pattern with a discounting cue (the verbal cues were negative while the accompanied nonverbal messages were positive).

Participants' attitudes toward the product were measured for all four groups of conditions immediately after information exposure. A second measurement was taken two weeks after the first one.

\section{Procedure}

The research was presented to participants as a marketing survey for a new (fictitious) product. To increase involvement, participants were asked to take part in a marketing research on a new product that was scheduled to be imported in the near future. Participants were informed that their opinion was highly important for gaining insights that would be used to develop a marketing strategy for this new product called "Student Relief".

The experiment consisted of two phases. In the first phase, all participants were shown a video containing a persuasive message. Group-A's video contained a persuasive positive congruent message regarding the product. In this video, the verbal communication and the nonverbal communication were positive $(\mathrm{V}+\mathrm{N}+)$. Participants in Group-B watched a video containing a persuasive message of leakage discrepancy regarding the product in which the verbal communication was positive, but the nonverbal communication was negative $(\mathrm{V}+\mathrm{N})$. In this video, the discounting information regarding the brand was transmitted by the nonverbal communication (the discounting cue). The discounting cue and the persuasive message were both presented in the video as an integrated message. Participants in Group-C saw a video that contained a negative congruent message regarding the product. In this video, the verbal communication and the nonverbal communication were negative (V-N-). Participants in Group-D watched a video containing a persuasive message of adaptive discrepancy regarding the product in which the verbal communication was negative, but the nonverbal communication was positive $(\mathrm{V}-\mathrm{N}+)$. In this video, the discounting information regarding the brand was transmitted by the verbal communication (the discounting cue). The discounting cue and the persuasive message were both presented in the video as an integrated message.

After being shown the videos, participants in all groups' conditions completed a questionnaire with items that corresponded to the dependent measures of the research regarding the brand attitude. In order to assess attitudes, the questionnaire contained references to the participants' brand attitudes based on the ABC model of attitudes, which contained three dimensions: affect, behavior, and cognitive. Questions regarding the behavior dimension (intentions) included the following sample item: "Do you intent to purchase Student Relief?" Questions regarding the cognitive dimension sample item: "Do you think that 'Student Relief can improve the chances of succeeding in academic exams?" Questions regarding the affect dimension (feelings and emotions) included the following sample item: "Do you feel that 'Student Relief' will prevent stress or anxiety?" 
Citation: Shapira M, Amar M, Grebelsky-Lichtman T (2017) The Positive Effect of Contradictory Information: The Effect of Verbal/Nonverbal Discrepancy on Brand Attitudes in the Short Term and the Long Term. J Account Mark 6: 253. doi: 10.4172/2168-9601.1000253

Page 5 of 10

In the second phase, two weeks after the immediate measurement, participants again completed the questionnaire with items that corresponded to the dependent measures of the research regarding their brand attitudes.

\section{The discounting cue}

The discounting cue was presented in one of the communication modes. In the leakage discrepancy condition, the discounting cue was presented in the nonverbal communication. While the verbal communication contained a positive content about the product, the accompanying nonverbal communication contained a negative expression that served as a discounting cue. Negative nonverbal information was established by facial expressions of dissatisfaction, tension, and stress; gestures of warning and threat; and body postures of enclosing, retreating, and anxiety.

In the adaptive discrepancy condition, the verbal communication, which was combined with the nonverbal communication, contained the discounting cue. While the nonverbal communication contained a positive orientation of satisfaction and recommendation of the product, the accompanied verbal communication contained a negative expression that served as a discounting cue. Negative verbal information was established by speech acts including uncertainty, stress, insecure, warning, and threats.

In the negative congruency condition, the verbal and the nonverbal messages were consistent and both communication modes expressed negative information.

\section{Dependent measures}

The study's questionnaire consisted of 15 items that tapped into participants' reflecting attitudes toward the Student Relief product. Sample items included: "In your opinion, is the Student Relief a highquality product?"; "In your opinion, is Student Relief suitable for a wide target audience?" and "In your opinion, will Student Relief succeed in the market?" Participants responded to the items on a seven-point scale ranging from 1 (definitely not) to 7 (certainly). Based on results of a Cronbach's alpha test, the internal validity of the questionnaire was $\alpha=0.97$. Additionally, all participants were asked to write down any information about the product that they remembered from the video they had seen.

\section{Manipulation check}

A preliminary manipulation check was conducted to ensure that the persuasive message was indeed persuasive and that the discounting cue was strong enough to discredit the persuasive message in an immediate measurement. Forty participants (who were not included in the following experiment) were randomly assigned to two conditions: a congruent message condition (in which participants were exposed to the congruent persuasive message) and a discounting cue condition (in which participants were exposed the leakage discrepant message that contained the discounting nonverbal cue). A t-test for independent samples was performed on the mean brand attitude scores, revealing a significant difference $(\mathrm{t}(39)=3.85, \mathrm{p}<0.002)$ between the mean scores in both conditions $(\mathrm{M}=3.42, \mathrm{SD}=1.13$ for the congruent message condition and $\mathrm{M}=2.69, \mathrm{SD}=1.99$ for the discounting cue condition of leakage discrepant message). These findings confirmed that the manipulation was effective.

\section{Results}

\section{The effect of verbal/nonverbal discrepant/congruent patterns on brand attitude}

Table 1 indicates positive brand attitudes for participants in the positive congruency condition, with a mean brand attitude score of $\mathrm{M}=5.85(\mathrm{SD}=0.8)$ in the immediate measurement. This positive product attitude for this type of a combined verbal and nonverbal message provided support for Hla. As predicted, the positive congruent pattern was the most persuasive message in the immediate measurement of the cognitive, affective, and behavioral components of brand attitudes.

In contrast, participants who were exposed to leakage discrepancy, with a nonverbal discounting cue, demonstrated less-positive brand attitudes. In this group, the mean brand attitude was less-positive than the constructive pattern of positive congruency to $\mathrm{M}=4.08$ ( $\mathrm{SD}=0.67$ ) in the immediate measurement (Table 1). These findings showed the effect of the negative nonverbal discounting cue, which was expressed by a decrease in positive product attitudes in the leakage discrepancy condition, supporting H1a.

This gap in attitude scores between the constructive pattern of positive congruency and the inhibitory pattern of leakage discrepancy was significant $(\mathrm{t}(211)=8.708, \mathrm{p}<0.001)$; (Figure 2).

Regarding adaptive discrepancy, which contains a positive nonverbal communication, accompanied by negative verbal communication as a discounting cue, participants in the adaptive discrepancy condition

\begin{tabular}{|c|c|c|c|}
\hline Condition & $\begin{array}{l}\text { Component of } \\
\text { attitude }\end{array}$ & $\begin{array}{c}\text { Immediate } \\
\text { measurement }\end{array}$ & Delayed measurement \\
\hline \multirow[t]{4}{*}{$\begin{array}{c}\text { Positive } \\
\text { congruency }\end{array}$} & Overall & $\begin{array}{l}M=5.85 \\
S D=0.8\end{array}$ & $\begin{array}{l}M=5.17 \\
S D=1.2\end{array}$ \\
\hline & Cognitive & $\begin{array}{l}M=5.75 \\
S D=0.63\end{array}$ & $\begin{array}{l}M=5.07 \\
S D=0.93\end{array}$ \\
\hline & Affective & $\begin{array}{l}M=5.82 \\
S D=1.03\end{array}$ & $\begin{array}{l}M=5.18 \\
S D=1.22\end{array}$ \\
\hline & Behavior & $\begin{array}{l}M=5.97 \\
S D=0.71\end{array}$ & $\begin{array}{l}M=5.27 \\
S D=1.21\end{array}$ \\
\hline \multirow{4}{*}{$\begin{array}{c}\text { Adaptive } \\
\text { discrepancy } \\
\text { Verbal } \\
\text { discounting cue } \\
\text { condition }\end{array}$} & Overall & $\begin{array}{l}M=5.39 \\
S D=1.23\end{array}$ & $\begin{array}{l}M=5.97 \\
S D=0.92\end{array}$ \\
\hline & Cognitive & $\begin{array}{l}M=5.25 \\
S D=1.18\end{array}$ & $\begin{array}{l}M=5.79 \\
S D=0.83\end{array}$ \\
\hline & Affective & $\begin{array}{l}M=5.37 \\
S D=1.13\end{array}$ & $\begin{array}{c}M=5.91 \\
S D=0.97\end{array}$ \\
\hline & Behavior & $\begin{array}{l}M=5.41 \\
S D=1.33\end{array}$ & $\begin{array}{l}M=6.21 \\
S D=1.01\end{array}$ \\
\hline \multirow{4}{*}{$\begin{array}{l}\text { Leakage } \\
\text { discrepancy } \\
\text { Nonverbal } \\
\text { discounting cue } \\
\text { condition }\end{array}$} & Overall & $\begin{array}{l}M=4.08 \\
S D=0.67\end{array}$ & $\begin{array}{l}M=3.60 \\
S D=1.16\end{array}$ \\
\hline & Cognitive & $\begin{array}{l}M=4.45 \\
S D=0.42\end{array}$ & $\begin{array}{c}M=3.7 \\
S D=1.21\end{array}$ \\
\hline & Affective & $\begin{array}{l}M=3.95 \\
S D=0.78\end{array}$ & $\begin{array}{l}M=3.47 \\
S D=1.12\end{array}$ \\
\hline & Behavior & $\begin{array}{c}M=3.81 \\
S D=0.81\end{array}$ & $\begin{array}{l}M=3.62 \\
S D=1.19\end{array}$ \\
\hline \multirow[t]{4}{*}{$\begin{array}{l}\text { Negative } \\
\text { congruency }\end{array}$} & Overall & $\begin{array}{l}M=3.98 \\
S D=1.01\end{array}$ & $\begin{array}{l}M=3.80 \\
S D=0.89\end{array}$ \\
\hline & Cognitive & $\begin{array}{l}M=4.65 \\
S D=1.03\end{array}$ & $\begin{array}{c}M=3.71 \\
S D=1.04\end{array}$ \\
\hline & Affective & $\begin{array}{l}M=4.65 \\
S D=0.78\end{array}$ & $\begin{array}{c}M=3.8 \\
S D=0.81\end{array}$ \\
\hline & Behavior & $\begin{array}{l}M=4.65 \\
S D=1.27\end{array}$ & $\begin{array}{l}M=2.92 \\
S D=0.86\end{array}$ \\
\hline
\end{tabular}

M: Mean; SD: Standard deviations.

Table 1: The effect of multimodal communication on attitudes change at an immediate measurement and overtime. 
Citation: Shapira M, Amar M, Grebelsky-Lichtman T (2017) The Positive Effect of Contradictory Information: The Effect of Verbal/Nonverbal Discrepancy on Brand Attitudes in the Short Term and the Long Term. J Account Mark 6: 253. doi: 10.4172/2168-9601.1000253

Page 6 of 10

demonstrated positive brand attitudes. In this group, the mean brand attitude was $\mathrm{M}=5.39(\mathrm{SD}=1.23)$ in the immediate measurement (Table 1). This confirmed H1b, which argued that adaptive discrepancy is a constructive and effective communication pattern for persuasion.

However, as shown in Table 1, participants in the negative congruency condition showed less-positive brand attitudes than participants in the adaptive discrepancy message condition, with a mean brand attitude score of $\mathrm{M}=3.98(\mathrm{SD}=1.01)$ in the immediate measurement. This expression of less-positive product attitudes for this type of a combined verbal and nonverbal message supported H1b.

This gap in attitude scores between the constructive pattern of adaptive discrepancy and the inhibitory pattern of negative congruency was significant $(\mathrm{t}(211)=7.05, \mathrm{p}<0.001$ (; see Figure 2 .

Together, these findings provide clear evidence for the presented framework of discrepant/congruent verbal and nonverbal patterns, and constitute support for H1a and H1b. In accordance with the proffered framework, participants exposed to the persuasive message in the constructive patterns of positive congruency (positive congruent message condition), and adaptive discrepancy (with a discounting verbal message) showed positive product attitudes in the immediate measurement. In contrast, participants exposed to the inhibited communication patterns of leakage discrepancy (with a nonverbal discounting cue), and negative congruency, demonstrated less-positive attitudes in the immediate measurement.

These findings demonstrate the significant influence that the relationship between verbal and nonverbal communication has on brand attitudes. The findings show that not all congruency is constructive and effective for persuasion, and that not all discrepancy is inhibitive. These communication patterns make it possible to formulate a comprehensive picture regarding the nature of verbal and nonverbal interrelations that should be beneficial or detrimental for persuasion and brand attitudes. In particular, persuasive messages that contain positive congruency and adaptive discrepancy activate positive brand attitudes. Persuasive messages of negative congruency and leakage discrepancy activate less-positive brand attitudes.

\section{The long-term effect of discrepant/congruent verbal/ nonverbal interrelations on brand attitudes}

Table 1 clearly indicates a decline in brand attitudes for participants in the positive congruent message condition over time, from a mean brand attitude score of $\mathrm{M}=5.85(\mathrm{SD}=0.8)$ in the immediate measurement to $\mathrm{M}=5.17(\mathrm{SD}=1.2)$ in the delayed measurement. Results of a t-test confirmed the statistical significance of this decline in the mean attitudes of participants in the positive congruent message group $(\mathrm{t}(201)=6.12, \mathrm{p}<0.001)$; (Table 1$)$. This decline in positive product attitudes over time supports H2a.

However, in contrast to H2a, participants who were exposed to the adaptive discrepancy condition, with the verbal discounting cue, demonstrated an increase in positive brand attitudes over time (Figure 2). In this group, the mean brand attitude increased from $M=5.39$ $(\mathrm{SD}=1.23)$ in the immediate measurement to $\mathrm{M}=5.97 \quad(\mathrm{SD}=0.92)$ in the delayed measurement. The increase in attitude scores over time was significant $(t(201)=6.72, p<0.001)$. These findings showed, unexpectedly, that the most effective persuasive pattern over time is adaptive discrepancy, which contains contradictory information.

Together, these findings reflected the complex influence of the sleeper effect. Participants who were exposed only to the persuasive positive congruency pattern (positive congruent message condition) showed a decline in positive product attitudes over time. However, participants in the adaptive discrepancy pattern with a verbal discounting cue demonstrated an increase in positive attitudes over time. A mixed two-way ANOVA with positive congruency communication (positive congruent message condition vs. adaptive discrepancy condition with a verbal discounting cue) as a betweensubject factor, and time of measurement (immediate vs. delayed) as a within-subject factor, confirmed the statistical significance of this interaction $(\mathrm{F}(1)=107.68, \mathrm{p}<0.001)$. This interaction demonstrated the sleeper effect, and expressed the positive effect of contradict information through adaptive discrepancy communication.

Regarding H2b, the crucial demand for the occurrence of the sleeper

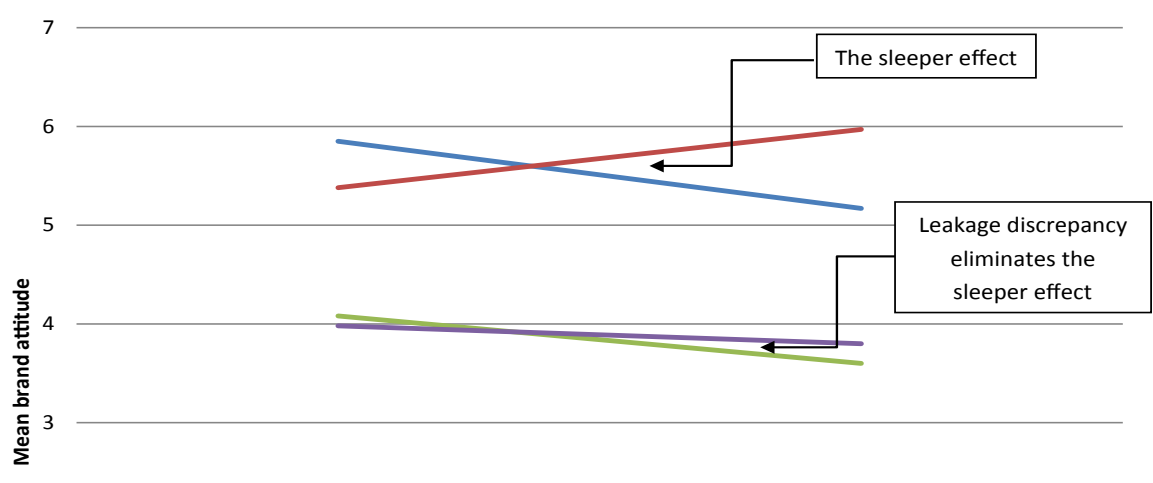

2

1

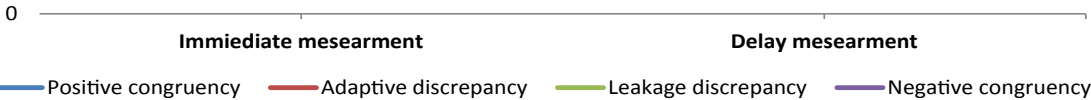

Figure 2: The effect of discrepant/congruent patterns on brand attitudes in the short and the long term. 
Citation: Shapira M, Amar M, Grebelsky-Lichtman T (2017) The Positive Effect of Contradictory Information: The Effect of Verbal/Nonverbal Discrepancy on Brand Attitudes in the Short Term and the Long Term. J Account Mark 6: 253. doi: 10.4172/2168-9601.1000253

effect-the increase in attitude change over time in the discounting cue group-was blocked in the condition in which participants were exposed to a persuasive message with a nonverbal discounting cue. The leakage discrepancy group did not demonstrate the typical increase in positive product attitudes over time. Particularly, the sleeper effect was not established when the discounting cue was displayed in the nonverbal mode of communication. In this group, there was no significant change in brand attitudes from the immediate measurement $(\mathrm{M}=4.08, \mathrm{SD}=0.67)$ to the delayed measurement $(\mathrm{M}=3.60, \mathrm{SD}=1.16)$. In fact, the nonverbal discounting cue group showed a non-significant directional (decreasing) effect $(\mathrm{t}(201)=3.95, \mathrm{p}>0.05)$; (Figure 2). This inhibition in increase of positive attitude change over time, which is a necessary condition to the demonstration of the sleeper effect, eliminated the sleeper effect in the nonverbal discounting cue condition. The nonverbal communication mode was very influential and the nonverbal discounting cue had a long-term effect and stayed in the memory of the participants for the delay measurement, eliminating the sleeper effect. Therefore, H2b was not confirmed.

A mixed two-way ANOVA with positive congruent message condition (positive congruent message condition vs. leakage discrepancy condition with a nonverbal discounting cue) as a betweensubject factor, and time of measurement (immediate vs. delayed) as a within-subject factor, did not confirm the statistical significance of this interaction $(\mathrm{F}(1)=56.42$, NS $)$.

Moreover, in contrast to $\mathrm{H} 2 \mathrm{~b}$, participants who were exposed to negative congruency condition, with the verbal and nonverbal discounting cue, did not demonstrate an increase in positive brand attitudes over time. In this group, the mean brand attitude increased slightly, from $\mathrm{M}=3.98(\mathrm{SD}=1.01)$ in the immediate measurement to $\mathrm{M}=3.80(\mathrm{SD}=0.89)$ in the delayed measurement. This minor increase in attitude scores over time was not significant $(t(201)=1.17$, NS). These findings showed the dominant effect of negative verbal communication, combined with negative nonverbal communication. Therefore, $\mathrm{H} 2 \mathrm{~b}$ was not confirmed.

The long-term effect of verbal/nonverbal interrelations on brand attitudes can be summarized by the following cumulative findings:

a. A significant decline in attitude change in the positive congruent message group;

b. A significant increase in behavioral attitude change in the adaptive discrepancy group with a verbal discounting cue;

c. A non-significant directional decline in brand attitudes in the nonverbal discounting cue condition, of the leakage discrepancy group;

d. A non-significant directional increase in brand attitudes in the negative congruent group. These findings confirmed the differential long-term effect of the discounting cue as a function of the communication mode in which it was expressed at the original point of exposure, and particularly the long-term effect of the nonverbal mode.

\section{Verbal versus nonverbal primacy}

To test our assumption that the nonverbal discounting cue was indeed the source of the differences in the results patterns, analysis for independent samples was conducted on the immediate and the delayed measurement of the brand attitude data. This was done by comparing brand attitudes of participants in the verbal discounting condition of adaptive discrepancy pattern with attitudes of participants in the nonverbal discounting cue condition of leakage discrepancy pattern. Findings revealed a significant difference $(t(99)=5.758, p<0.001)$ between the nonverbal discounting cue condition $(\mathrm{M}=4.08, \mathrm{SD}=0.67)$ and the verbal discounting cue condition $(\mathrm{M}=5.39, \mathrm{SD}=1.23)$ in the immediate measurement supporting our assumption. The analysis of the delayed measurement also supported our assumption and revealed a significant difference $(\mathrm{t}(201)=6.82, \mathrm{p}<0.001)$ between the nonverbal discounting cue condition (leakage discrepancy) $(\mathrm{M}=3.60, \mathrm{SD}=1.16)$ and the verbal discounting cue condition (adaptive discrepancy) $(\mathrm{M}=5.97, \mathrm{SD}=0.92)$. In both the short and long term, the nonverbal communication mode, as a discounting cue, was dominant and was more influential than the verbal communication mode, as a discounting cue (Figure 2).

\section{Discussion}

The main objective of this research was to develop an analytical and theoretical framework that assesses the effects of verbal and nonverbal interrelations on brand attitudes. This research broadens the theoretical multimodal communication approach into the effects of verbal and nonverbal congruency/discrepancy patterns on persuasion and explains the complex process that influences brand attitudes. This research produced some unexpected findings regarding the effects on brand attitudes, which enabled us to create a tapestry of effective and inhibitory communication patterns. This tapestry explains the communication patterns that activate persuasion.

The present research offers empirical contribution and theoretical insights by developing the short-term and long-term effects of multimodal communication on brand attitudes. The research expands the sleeper effect literature into verbal/nonverbal interconnections and uniquely bridges the sleeper effect and the multimodal communication approach, thereby explaining the long-term effect of verbal/nonverbal interrelations on brand attitudes.

The proposed framework expands the theoretical framework of channel primacy [36-38] by providing a composite theoretical account of the influence of various discrepancy patterns on persuasion. The present research makes a unique contribution by addressing this issue. The research extends reliance theories and presents an explanation of the conditions under which a discounting cue in one of the communication modes in various discrepancy patterns that contains contradictory verbal and nonverbal communication has a short and long-term impact on attitude change. The novel contribution of the present research is its delineation of a comprehensive picture of the relative dominance of verbal versus nonverbal communication modes in persuasion. Based on the novel findings, a set of conclusions were formulated:

\section{Verbal/nonverbal interrelations effect brand attitudes}

The presented theoretical and analytical framework develops the multimodal communication approach $[1,2]$ that emphasizes the importance of examining the mutual relations between verbal and nonverbal modes of communication, and delineates the effects of various interrelations on brand attitudes and persuasion.

The innovative findings relate to the various effects of each verbal/ nonverbal interrelation on brand attitude. Most previous studies have examined these communication modes separately, focusing on either the verbal or the nonverbal mode. The current research expands the effect of verbal/nonverbal interrelations on brand attitudes, and establishes that a combined examination of verbal/nonverbal relationships provides new insights into the study of persuasion and 
Citation: Shapira M, Amar M, Grebelsky-Lichtman T (2017) The Positive Effect of Contradictory Information: The Effect of Verbal/Nonverbal Discrepancy on Brand Attitudes in the Short Term and the Long Term. J Account Mark 6: 253. doi: 10.4172/2168-9601.1000253

Page 8 of 10

brand attitudes. This is explained based on a cognitive perspective that argues that addressees receive verbal message accompanied with nonverbal message, and the way in which the overall message is perceived is determined by the relationship between the two modes $[4,5]$.

\section{Verbal/nonverbal congruency may have negative effect on brand attitudes}

The presented framework demonstrates that not all congruency is effective for persuasion, and not all discrepancy is inhibitive. Negative congruency, which contains a negative verbal and nonverbal communication, despite being consistent and clear, has an inhibitory effect on persuasion. This pattern has a negative effect and expends the evidence of studies in other fields of communication that argued that an overly negative message could arouse dislike and could threaten and undermine the credibility of the sender and the message [19-21].

Positive congruency, on the other hand, which contains positive verbal and nonverbal messages, activates positive attitudes toward a brad immediately after exposure. In all aspects of brand attitudes, the cognitive, emotional, and behavioral congruent message was effective. This confirms previous studies $[8,9]$ which explained that positive congruency presents a message that is certain, consistent, and convincing. Consequently, it is associated with credibility and trust and considered an effective pattern of communication, which may create an optimal condition for persuasion and achieving agreement. However, the unique findings of the current research are that this pattern is the most effective pattern only immediately after exposure. In the long run, the most effective pattern for persuasion is adaptive discrepancy.

\section{The positive effect of contradict information on brand attitudes}

This research uncovers a counterintuitive effect of positive persuasion effect of contradictory information, showing that specifiable conditions will be more favorably disposed to brand attitudes when verbal/nonverbal discrepancy is expressed than other types of verbal/ nonverbal congruency. Specifically, adaptive discrepancy, which is characterized by a negative verbal communication accompanied by a positive nonverbal communication, is an effective pattern for persuasion. This is explained by the fact that the negative verbal communication is received in a context of positive nonverbal content, and is therefore perceived as specific, less threatening, and impersonal. Positive nonverbal expression conveys a message of security and calmness that puts some distance from the negative verbal message, while the person expressing the message radiates something strong and supportive. This pattern mitigates the negative verbal message and helps establish a credible image of self-confidence, ease, and control. This type of discrepancy enhances cooperation [16] and expresses a pattern in which the gap between the channels and the verbal negative information may have a positive value for communication and persuasion. This is explained by the fact that the discounting verbal communication is received in a context of positive nonverbal content, and is therefore perceived as specific and less threatening. The positive nonverbal communication expresses security and calmness, which mitigates the negative verbal message and helps establish a credible image of self-confidence, ease, and control $[15,16]$.

This finding expands previous studies that pointed to the positive effect of adaptive discrepancy in interpersonal communication in achieving cooperation [7] and in political communication for success in televised debates [39]. The novel finding highlights the positive effect of adaptive discrepancy in persuasion.

\section{Verbal/nonverbal discrepancy has a long-term effect on brand attitudes}

This research presents novel findings regarding the positive longterm effect of adaptive discrepancy. Over time, adaptive discrepancy is the most effective pattern for persuasion. Even compared to positive congruency, in which both the verbal and the nonverbal communication express a positive message, adaptive discrepancy results in more positive brand attitudes.

Bridging multimodal communication approach and the sleeper effect exposes the long-term influence of verbal/nonverbal interrelations on brand attitude. Although the sleeper effect has attracted significant scientific attention, the present study is the first to explore this effect in verbal/nonverbal discrepancy/congruency communication.

Unexpectedly, an integrated analysis of the various verbal/ nonverbal interrelations in this research confirmed the classic sleeper effect. In the comparison between participants in the positive congruency group (showing the typical decrease in persuasion over time) and participants in the adaptive discrepancy group with a verbal discounting cue (showing an increase in persuasion over time), the sleeper effect was reflected [27-29].

The long-term effect of adaptive discrepancy may be explained based on the availability valence hypothesis, which argues that the attitude change over time is due to the valence and availability of relevant associations. At the outset, unfavorable verbal characteristics suppress associations with favorable nonverbal message content. At the time of delayed measurement, the favorable nonverbal message gains primacy.

\section{Leakage discrepancy negatively affects brand attitudes}

Leakage discrepancy, which contains a positive verbal communication accompanied by a negative nonverbal communication, had an inhibitory effect and established less positive brand attitudes. Leakage discrepancy leads to the message being discredited in terms of validity, inaccuracy and credibility $[6,12]$. This supports the explanation of low credibility source [25]. The present research expands past research and shows that the discounting nonverbal information suppressed immediate attitude change, leading participants in the nonverbal discounting cue group of leakage discrepancy to show lesspositive brand attitudes.

Moreover, the unique findings are that leakage discrepancy eliminates the sleeper effect and that the negative effect of the nonverbal discounting cue has a long-term influence. The driven mechanism of this elimination stemmed from the specific type of discrepancy and the different effect of each communication mode in the typical chain of events, leading to a sleeper effect. Over time, the footprint of the nonverbal discounting cue's information results in attitudes persistence, in contrast to the increase in attitudes demonstrated in the verbal discounting cue group, and the decrease in attitude change, revealed in the positive congruent message group.

In leakage discrepancy, the footprint of the discounting nonverbal message remained in memory. The nonverbal discounting cue led to a stronger representation in memory: the negative nonverbal information strengthened the cue's representation in memory, disrupted the dissociation between the original positive verbal message 
Citation: Shapira M, Amar M, Grebelsky-Lichtman T (2017) The Positive Effect of Contradictory Information: The Effect of Verbal/Nonverbal Discrepancy on Brand Attitudes in the Short Term and the Long Term. J Account Mark 6: 253. doi: 10.4172/2168-9601.1000253

Page 9 of 10

and nonverbal discounting cue and eliminated the sleeper effect that was clearly demonstrated in the adaptive discrepancy condition.

\section{Nonverbal communication has a primacy effect on brand attitude}

This research has developed reliance theories by exploring the effects of discrepant patterns of verbal/nonverbal communicationtermed the cue opposition paradigm [40] in order to assess which channel is the more important contributor to the process of persuasion and brand attitude. This research clearly supports the nonverbal dominance hypothesis $[41,42]$ and contradicts studies that points to verbal communication dominant, which argued that when discrepancy communication is expressed, the verbal messages gain preference.

The current research supports evidences for nonverbal primacy as a key element in distinguishing between primary and secondary sources of information in interpersonal contexts [36]. The developmental interactionist theory [2] explains the nonverbal dominance based on evolutionary perspectives [8] and is supported by research indicating that nonverbal communication gains primacy because the reception process of nonverbal cues is faster than the analysis of verbal messages [37]. As for persuasion, leakage discrepancy that contains a discounting cue in the nonverbal communication generated a high level of negative associations over time, resulting in the decrease in attitude change and eliminating the sleeper effect.

\section{Conclusions}

\section{Implications and additional avenues for future research}

The present research is highly relevant from a practical point of view regarding word to mouth marketing era, advertising, persuasion, and interpersonal communication. A deep understanding of this mechanism is highly relevant to communication and marketing contexts, in which persuasion messages use the verbal and nonverbal communication modes. The results of the current research may be applied in interpersonal communication. Future research could explore the proposed framework in various media platforms (internet, smartphone, tablets, smart TV, etc.) and screens to attract target audiences to a brand, as they struggle to gain attention and persuasion, particularly in the new media era, in the course of the audience navigation process in the visual field.

Insights gained from this research may be useful to maximize attaining persuasion by building a complex persuasive message that contains contradictory information in different communication modes displayed in integrated messages, on screen or in interpersonal communication. This counterintuitive effect offers an unusual communication strategic perspective. Paradoxically, in order to protect the original persuasive message from damage over time, the optimal communication pattern is adaptive discrepancy.

\section{References}

1. Jones SE, LeBaron CD (2002) Research on the relationship between verbal and nonverbal communication: Emerging integrations. Journal of Communication 52: 499-521.

2. Buck R, VanLear CA (2002) Verbal and nonverbal communication: Distinguishing symbolic, spontaneous and pseudo-spontaneous nonverbal behavior. Journal of Communication 52: 522-541.

3. Grebelsky-Lichtman T (2015) Parental response to child's incongruence: Verbal versus nonverbal primacy in parent-child interactions. Communication Monographs 82: 484-509.

4. Schults A, Tulviste T, Konstabel K (2012) Early vocabulary and gestures in Estonian children. Journal of Child Language 39: 664-686.
5. Burgoon JK (2006) Nonverbal signals. In: Knapp ML, Miller GR editors. Handbook of Interpersonal Communication, pp: 344-390

6. Ekman P (1997) Lying and deception. In: Stein NL, Ornstein PA, Tversky B, Brained $\mathrm{C}$ editors. Memory for everyday and emotional events, pp: 333-347.

7. Grebelsky-Lichtman T (2014) Parental patterns of cooperation in parent-child interactions: The relationship between nonverbal and verbal communication. Human Communication Research 40: 1-29.

8. Boone RT, Buck R (2003) Emotional expressivity and trustworthiness: The role of nonverbal behavior in the evolution of cooperation. Journal of Nonverbal Behavior 27: 163-182.

9. Bublitz W (1988) Supportive fellow-speakers and cooperative conversations Discourse topics and topical actions, participant roles and 'recipientaction' in a particular type of everyday conversation. John Benjamins Publishing Company.

10. DePaulo BM, Bell KL (1996) Truth and investment: Lies are told to those who care. Journal of Personality and Social Psychology 71: 703

11. O'sullivan M, Ekman P, Friesen W, Scherer KR (1985) What you say and how you say it: The contribution of speech content and voice quality to judgments of others. Journal of Personality and Social Psychology 48: 54.

12. Langer SL, Wurf E (1999) The effects of channel-consistent and channelinconsistent interpersonal feedback on the formation of metaperceptions. Journal of Nonverbal Behavior 23: 43-65.

13. Cappella JN, Greene JO (1982) A discrepancy-arousal explanation of mutual influence in expressive behavior for adult and infant-adult interaction 1 Communications Monographs 49: 89-114.

14. Weizman E (2008) Positioning in media dialogue: Negotiating roles in the news interview. John Benjamins Publishing.

15. Lessin S, Jacob T (1984) Multichannel communication in normal and delinquent families. Journal of Abnormal Child Psychology 12: 369-383.

16. Grebelsky-Lichtman T (2010) The relationship of verbal and nonverbal behavior to political stature: The political interviews of Israel's Prime Minister Ariel Sharon. Journal of Political Marketing 9: 229-253.

17. Goffman E (1979) Gender Advertisements. London: Macmillan.

18. Reinemann C, Maurer M (2005) Unifying or Polarizing? Short-Term Effects and Postdebate Consequences of Different Rhetorical Strategies in Televised Debates. Journal of Communication 55: 775-794.

19. Allen M, Burrell N (2002) The negativity effect in political advertising. Thousand Oaks, CA: Sage.

20. Benoit WL, Sheafer T (2006) Functional theory and political discourse: Televised debates in Israel and the United States. Journal of Mass Communication Quarterly 83: 281-297.

21. Cho J, Choy SP (2011) From podium to living room: Elite debates as an emotional catalysts for citizen communicative engagements. Communication Research 38: 778-804

22. DePaulo BM (1992) Nonverbal behavior and self-presentation. Psychological Bulletin 111: 203-243.

23. Babad E, Peer E (2010) Media bias in interviews' nonverbal behavior: Potentia remedies, attitude similarity and meta-analysis. Journal of Nonverbal Behavior 35: $57-78$.

24. DePaulo BM, Rosenthal R (1979) Ambivalence, discrepancy, and deception in nonverbal communication. Skill in nonverbal communication: Individual differences, pp: 204-248

25. Zuckerman M, DePaulo BM, Rosenthal R (1981) Verbal and nonverba communication of deception. Advances in Experimental Social Psychology 14 $1-59$.

26. Vrij A, Edward K, Roberts KP, Bull R (2000) Detecting deceit via paralysis of verbal and nonverbal behavior. Journal of Nonverbal Behavior 24: 239-263.

27. Eagly AH, Chaiken S (1993) The psychology of attitudes. Harcourt Brace Jovanovich College Publishers.

28. Kumkale GT, Albarracín D (2004) The sleeper effect in persuasion: a metaanalytic review. Psychological Bulletin 130: 143.

29. Steinhart $Y$, Carmon Z, Trope $Y$ (2013) Warnings of adverse side effects can backfire over time. Psychological science 24: 1842-1847. 
Citation: Shapira M, Amar M, Grebelsky-Lichtman T (2017) The Positive Effect of Contradictory Information: The Effect of Verbal/Nonverbal Discrepancy on Brand Attitudes in the Short Term and the Long Term. J Account Mark 6: 253. doi: 10.4172/2168-9601.1000253

Page 10 of 10

30. Mazursky D, Schul Y (1988) The effects of advertisement encoding on the failure to discount information: Implications for the sleeper effect. Journal of Consumer Research 15: 24-36

31. Kimball SH, Levy T, Venturelli H, Miller S (2014) Interactive Voice recognition communication in electoral politics: Exploratory metadata analysis. American Behavioral Scientist 58: 1236-1245.

32. Hovland Cl, Lumsdaine AA, Sheffield FD (1949) Experiments on mass communication. (Studies in social psychology in World War II).

33. Hovland $\mathrm{Cl}$, Weiss W (1951) The influence of source credibility on communication effectiveness. Public Opinion Quarterly 15: 635-650.

34. Miller N, Campbell DT (1959) Recency and primacy in persuasion as a function of the timing of speeches and measurements. The Journal of Abnormal and Social Psychology 59: 1.

35. Hannah DB, Sternthal B (1984) Detecting and explaining the sleeper effect. Journal of Consumer Research 11: 632-642.

36. Burgoon JK, Bonito JA, Ramirez A, Dunbar NE, Kam K, Fischer J (2002) Testing the interactivity principle: Effects of mediation, propinquity, and verbal and nonverbal modalities in interpersonal interaction. Journal of Communication 52: 657-677.

37. Lamy D, Salti M, Bar-Haim Y (2009) Neural correlates of subjective awareness and unconscious processing: an ERP study. Journal of Cognitive Neuroscience 21: $1435-1446$.

38. Mehrabian A (1981) Silent messages: Implicit communication of emotions and attitudes. Belmont, CA: Wadsworth.

39. Grebelsky-Lichtman T (2016) An Advanced Framework for Verbal Communication and Nonverbal Gestures in Parent-child Interactions. Studies in Media and Communication 4: 82-98.

40. Walker MB (1997) The relative importance of verbal and non-verbal cues in the expression of confidence. Australian Journal of Psychology 29: 45-57.

41. Grahe JE, Bernieri FJ (1999) The importance of nonverbal cues in judging rapport. Journal of Nonverbal Behavior 23: 253-269.

42. Walther JB, Loh T, Granka L (2005) Let me count the ways: The interchange of verbal and nonverbal cues in computer-mediated and face-to-face affinity. Journal of Language and Social Psychology 24: 36-65. 